\title{
Hereditary Cerebellar Ataxia
}

National Cancer Institute

\section{Source}

National Cancer Institute. Hereditary Cerebellar Ataxia. NCI Thesaurus. Code C140268.

Cerebellar ataxia that is transmitted from parent to child. 